\title{
Behavior of the guanosine monophosphate modified boron-doped diamond electrode in the presence of the pesticide alachlor
}

\author{
Jana Svítková, Lubomír Švorc, Ján Labuda \\ Institute of Analytical Chemistry, Faculty of Chemical and Food Technology, \\ Slovak University of Technology in Bratislava, Radlinského 9, SK-812 37 Bratislava, Slovak Republic \\ jana.svitkova@stuba.sk
}

\begin{abstract}
Alachlor (ALA) has been widely used in agriculture and may act as a carcinogen and an environmental estrogen. The present work deals with chemical modification of boron-doped diamond electrode (BDDE) by guanosine monophosphate (GMP) and its study in the presence of ALA. Cyclic voltammetry and electrochemical impedance spektroscopy in the presence of the redox indicator $1 \times 10^{-3} \mathrm{~mol} / \mathrm{L}\left[\mathrm{Fe}(\mathrm{CN})_{6}\right]^{3-/ 4-}$ together with differential pulse voltammetry of the nucleotide base were explored to test effects of GMP immobilization time, the pesticide concentrations and incubation time in the pesticide solution. It was found that GMP layer on the BDDE surface is distorted after incubation in the ALA solution.
\end{abstract}

Keywords: boron-doped diamond electrode, chemically modified electrode, guanosine monophosphate, DNA, alachlor

\section{Introduction}

Biosensors are widely used in clinical, environmental and food analysis. The detection of damage to the DNA belongs to one of the specific fields of analysis with utilization of DNA-based biosensors (Labuda, 2011; Labuda and Vyskočil, 2014). Owing to their specificity and sensitivity, biosensors have been increasingly developed for many applications, in environmental monitoring and control, food and drug analysis as well as detection of biological metabolites (Wang, 2008). Variations in the voltammetric signals of DNA bases can occur in the presence of active chemical agents when the electroactive sites of the bases are exposed to oxidation due to the breakage or unwinding of double-stranded DNA (Oliveira and Oliveira-Brett, 2010a). The detection of nucleotides in aqueous solution enables evaluation of the interaction and/or binding of chemical species to the components of the DNA (Garbellini et al., 2011). Damage to DNA in the cells and/or in the double helix structure of biomolecule with toxic compounds may cause mutations that can result in the development of cancers (Jackson and Bartek, 2009). The electrochemical behavior of DNA and its components at different types of electrochemical transducers has been investigated for a number of years, first using mercury (Paleček, 1960) electrodes and later solid electrodes, such as pyrolytic graphite electrodes (Dryhurts, 1971), glassy carbon electrodes (Oliveira-Brett et al., 2002) and screen printed carbon electrodes (Labuda et al., 2009). Boron-doped diamond (BDD) is a modern electrode material which opens new possibilities of electro- chemical investigations due to its excellent features, such as the wide potential window in aqueous solutions, low background current, long-term stability of response, mechanical robustness and compatibility with biological materials (Svítková et al., 2012; Švorc et al., 2012; Švorc et al., 2013a). Advantages of the boron-doped diamond electrode (BDDE) compared to conventional carbonaceous electrodes, particularly for the electrochemical oxidation (Švorc et al., 2013a; Švorc et al., 2013b; Švorc et al., 2015). Concerning the DNA components, there have been few papers dealing with determination of purine and pyrimidine bases using BDDE (Apilux et al., 2007; Ivandini et al., 2007; Karasz et al., 2005; Oliveira and OliveiraBrett, 2010b; Švorc and Kalcher, 2014).

The assembly of biomolecules on solid supports is important for the development of biosensors and biochips (Troupe et al., 1998). Protein and DNA attachment to glass, silicon and gold surfaces can be prone to degradation over time. In this sense, Hamers and co-workers suggested that diamond could be an ideal platform for future biochips because of its superior mechanical, thermal, chemical and electrical properties (Yang et al., 2002). The DNA-modified diamond substrates were shown to be highly selective and robust in the subsequent hybridization processes (Knickerbocker et al., 2003). The versatility of the BDD electrode material has also been utilized for the development of sensors and biosensors (Svítková et al., 2015).

Damage to DNA caused by toxic compounds including pesticides can hinder processes of transcription and replication, resulting in arrest the cell cycle, cell death and mutations (Creus et 
al., 2011). The guanosine (GMP) and adenosine (AMP) monophosphate DNA nucleotides have important biological functions in the body (Yin et al., 2011). Changes in the chemical structures and/ or decreased availability of these nucleotides in the body can affect their biological functions (Ravera et al., 2007). Voltammetric and nanogravimetric DNA biosensors were applied to study of the toxicity and DNA damage caused by pesticides (Nowicka et al., 2010). In other work, the BDDE was used to evaluate the interaction of the nucleotides GMP and AMP with the organophosphorus pesticides as chlorpyrifos, metamidophos and monocroptophos. The interactions could be explained by the binding of the pesticides to nitrogenous bases present in the nucleotides. On the other hand, no oxidation peaks related to oxidative damage, opening of the double helix or DNA unwinding were detected in studies of the interactions of these pesticides with calf thymus dsDNA, which were also performed using the BDDE (Garbellini et al., 2013).

Alachlor [2-chloro-N-2, 6-diethylphenyl-N-(methoxymethyl) acetamide] (ALA) is a popular chloroacetanilide herbicides from the group with a high risk factor for human health (eye and skin irritation, organ damage, cancer) (Bernasinska et al., 2013). In fact, it has been classified as a B2 carcinogen by Environmental Protection Agency (EPA, US), and it is one of the priority substances listed by the European Commission within the scope of the Water Framework Directive (Zhu et al., 2006). Residual amounts of this herbicide in soil not only appear in the products of vegetables and fruits but also are transferred to other areas by the underground water system to damage the biological system. Although ALA is toxic to many organisms, conventional biological remediation processes are not suitable to remove this substance from contaminated water and therefore alternative treatment methods and reliable analytical methods are required for effective removal of the herbicides and their monitoring (Bagal and Gogate, 2012).

The present paper demonstrates simple application of BDDE as a substrate for the modification by GMP and DNA. We have tried to point out the fact that such modified BDDE could be utilized for the examination behavior of GMP and DNA with ALA. As far as we know, there is lack of papers concerning the use of doped diamond electrodes for the study of DNA nucleotides with pesticides.

\section{Experimental}

\section{Chemical and reagents}

Alachlor (ALA, purity of $99.2 \%$ ), guanosine monophosphate (GMP, purity of $98 \%$ ) and double stranded DNA (dsDNA, fish sperm) were obtained from Sigma-Aldrich (USA). The stock solution of GMP ( $2 \mathrm{mg} / \mathrm{mL}$ ) was prepared by dissolving suitable amounts of solid standard in $2 \mathrm{~mL}$ of sodium hydroxide $(0.2 \mathrm{~mol} / \mathrm{L})$ followed by dilution with deionized water to the desired volume. The stock solutions of ALA $\left(4.5 \times 10^{-3} \mathrm{~mol} / \mathrm{L}\right)$ and dsDNA $(2 \mathrm{mg} / \mathrm{mL})$ were prepared in deionized water and stored at $4{ }^{\circ} \mathrm{C}$. Working solutions of lower concentrations were freshly made on the day of experiment by diluting the particular stock solution with supporting electrolyte. The supporting electrolyte was $0.1 \mathrm{~mol} / \mathrm{L}$ phosphate buffer solution (PBS, $\mathrm{pH}=6.9$ ) which was made by usual way by dissolution of $\mathrm{Na}_{2} \mathrm{HPO}_{4} \cdot 12 \mathrm{H}_{2} \mathrm{O}, \mathrm{NaH}_{2} \mathrm{PO}_{4} \cdot 10 \mathrm{H}_{2} \mathrm{O}$ and $\mathrm{KCl}$ in deionized water. The stock mixture solution of $1 \times 10^{-3} \mathrm{~mol} / \mathrm{L} \mathrm{K}_{3}\left[\mathrm{Fe}(\mathrm{CN})_{6}\right]$ and $\mathrm{K}_{4}\left[\mathrm{Fe}(\mathrm{CN})_{6}\right]$ (Lachema, Brno) was prepared in deionized water and added to the required volume with PBS. Other chemicals were used of analytical reagent grade purity. The deionized water with resistivity above $18 \mathrm{M} \Omega \cdot \mathrm{cm}$ was used throughout the experiments.

\section{Apparatus}

All electrochemical experiments were conducted in a three electrode set up. The cell consisted of $\mathrm{Ag} /$ $\mathrm{AgCl}(3 \mathrm{~mol} / \mathrm{L} \mathrm{KCl}$ ) reference electrode, a platinum wire as the counter electrode and BDDE (boron doping level of $1000 \mathrm{ppm}$, electrical resistivity of $0.075 \Omega \cdot \mathrm{cm}$ ) purchased in an inert polyether ether ketone (PEEK) body with inner diameter of $3 \mathrm{~mm}$ (Windsor Scientific Ltd., UK) served as the working electrode. All potentials reported in this paper were obtained vs. $\mathrm{Ag} / \mathrm{AgCl}(3 \mathrm{~mol} / \mathrm{L} \mathrm{KCl})$ electrode at an ambient temperature of $25{ }^{\circ} \mathrm{C}$. Electrochemical measurements were carried out using an Autolab PGSTAT 302N (Metrohm Autolab B.V., The Netherlands) potentiostat/galvanostat controlled with the NOVA software of 1.10 version. The electrochemical properties of the unmodified and the modified BDD electrode were studied by cyclic voltammetry (CV) and electrochemical impedance spectrometry (EIS) using $1 \times 10^{-3} \mathrm{~mol} / \mathrm{L}\left[\mathrm{Fe}(\mathrm{CN})_{6}\right]^{3-/ 4-}$ in $0.1 \mathrm{~mol} / \mathrm{L} \mathrm{PBS}$ $(\mathrm{pH}=6.9)$ and differential pulse voltammetry (DPV) using $0.1 \mathrm{~mol} / \mathrm{L}$ PBS $(\mathrm{pH}=6.9)$. All $\mathrm{pH}$ values were measured with $\mathrm{pH}$ meter Model 215 (Denver Instrument, USA), which was weekly calibrated with standard buffer solutions.

\section{Preparation of the GMP and DNA modified $B D D E$}

At the beginning, the BDDE was rinsed with deionized water and gently rubbed with a piece of damp silk cloth until a mirror-like appearance of surface was obtained (with minimal probability of mechanical surface damage). The GMP and DNA modified BDDE (GMP/BDDE and DNA/BDDE) 
were constructed by the simple dropping of $8 \mu \mathrm{L}$ of GMP and/or DNA stock solution, respectively, onto the BDDE surface and evaporation to dryness (12 h). Subsequently, the prepared sensors were immersed into PBS for 2 min under stirring to achieve equilibrium conditions.

\section{Techniques}

Cyclic voltammetry $(C V)$ : the electrode was immersed in $1 \times 10^{-3} \mathrm{~mol} / \mathrm{L}$ mixture of the redox indicator $\left[\mathrm{Fe}(\mathrm{CN})_{6}\right]^{3-/ 4-}$ in $0.1 \mathrm{~mol} / \mathrm{L} \mathrm{PBS}(\mathrm{pH}=6.9)$ for $2 \mathrm{~min}$ under stirring. Afterwards, cyclic voltammograms were recorded within a potential range from -0.7 to $+0.7 \mathrm{~V}$ at a scan rate of $50 \mathrm{mV} \cdot \mathrm{s}^{-1}$ and a step potential of $5 \mathrm{mV}$.

Electrochemical impedance spectroscopy (EIS): the measurements were carried out in $1 \times 10^{-3} \mathrm{~mol} / \mathrm{L}$ $\left[\mathrm{Fe}(\mathrm{CN})_{6}\right]^{3-/ 4-}$ in $0.1 \mathrm{~mol} / \mathrm{L}$ PBS $(\mathrm{pH}=6.9)$ at a polarization potential of $0.2 \mathrm{~V}$ (corresponding to a formal potential of the redox indicator used) in a frequency range of $0.1-50000 \mathrm{~Hz}$ (in 50 frequency steps) with an amplitude of $10 \mathrm{mV}$.

Differential pulse voltammetry (DPV): these measurements were performed in $0.1 \mathrm{~mol} / \mathrm{L} \mathrm{PBS}(\mathrm{pH}=6.9)$ with the parameters: modulation amplitude of $25 \mathrm{mV}$, modulation time of $50 \mathrm{~ms}$ and step potential of $5 \mathrm{mV}$.

\section{Procedure}

First, the $\mathrm{CV}$ and EIS measurements were performed with the GMP/BDDE and DNA/BDDE in the presence of $1 \times 10^{-3} \mathrm{~mol} / \mathrm{L}\left[\mathrm{Fe}(\mathrm{CN})_{6}\right]^{3-/ 4-}$ in $0.1 \mathrm{~mol} / \mathrm{L} \mathrm{PBS}(\mathrm{pH}=6.9)$ as described above. The stability of the BDDE modification was checked after rinsing it with deionized water and incubation in $\operatorname{PBS}(\mathrm{pH}=6.9)$ for a certain period $(2,7,12$, $17 \mathrm{~min}$ ) under stirring. After washing the electrode by deionized water and the medium exchange for $1 \times 10^{-3} \mathrm{~mol} / \mathrm{L}\left[\mathrm{Fe}(\mathrm{CN})_{6}\right]^{3-/ 4-}$ in $0.1 \mathrm{~mol} / \mathrm{L} \mathrm{PBS}$ $(\mathrm{pH}=6.9)$, the $\mathrm{CV}$ and EIS measurements were again executed. The same approach was applied to the incubation of the modified electrodes in the ALA solution $\left(c=4.5 \times 10^{-5} \mathrm{~mol} / \mathrm{L}\right)$ for given time. Concerning the immobilized GMP, its portion (surv GMP) that survived in the immobilized state after the incubation of the modified electrode in the ALA solution was expressed as the normalized response, which was calculated according to the Eq. 1:

$$
\begin{gathered}
\Delta I_{\text {rel }}= \\
=\left[\left(I_{\text {surv,GMP }}-I_{\text {bare,BDDE }}\right) /\left(I_{\mathrm{GMP}}-I_{\text {bare,BDDE }}\right)\right] \times 100
\end{gathered}
$$

where $I_{\text {surv,GMP }}$ and $I_{\mathrm{GMP}}$ are the $\mathrm{CV}$ anodic currents for $1 \times 10^{-3} \mathrm{~mol} / \mathrm{L}\left[\mathrm{Fe}(\mathrm{CN})_{6}\right]^{3-/ 4-}$ in $0.1 \mathrm{~mol} / \mathrm{L} \mathrm{PBS}$ $(\mathrm{pH}=6.9)$ the GMP/BDDE measured at the peak potential recorded at the bare BDDE without GMP (i.e., at $0.15 \mathrm{~V}$ ) at which the $I_{\mathrm{BDDE}}$ value was obtained.
The experiments were repeated three times. The reproducibility of the responses expressed as RSD $(n=3)$ obtained on the bare BDD electrode as well as those covered by GMP was lower than $10 \%$. This was the reason why the normalized values of the responses were used.

\section{Results and Discussion}

The study of the pesticide ALA with the GMP/ BDDE and DNA/BDDE was investigated using the ALA concentrations ranging from $4.5 \times 10^{-6}$ to $4.5 \times 10^{-4} \mathrm{~mol} / \mathrm{L}$. These values represent common residue levels of this pesticide found in the environment with negative effects for humans and animals (Greene and Pohanish, 2005).

First, the GV scan was applied to elucidate the electrochemical behavior of ALA on the bare BDDE and its possible adsorption on the electrode. After an incubation of the electrode in ALA solutions for various time intervals (up to several hours), only negligible changes in the redox indicator $\mathrm{CV}$ response were observed. This can be assigned to the fact that the studied herbicide does not adsorb considerably on the BDDE surface.

The $\left[\mathrm{Fe}(\mathrm{CN})_{6}\right]^{3-/ 4-}$ system is also valuable and convenient tool to monitor a barrier effects at the working electrode. Fig. 1 depicts cyclic voltammograms recorded at the modified electrodes (GMP/BDDE and DNA/BDDE) which show significant decrease of the anodic peak current response of the redox indicator (the lowest peak current) comparing to bare BDDE (the highest peak current). The stability of the BDDE modification after incubation in PBS $(\mathrm{pH}=6.9)$ for a certain time period $(2,7,12,17 \mathrm{~min})$ under stirring has been confirmed.

Subsequently, after an incubation of the modified BDDE electrodes in ALA solution, an increase in the anodic current response and a mild decrease of the peak to peak potential separation of the redox indicator were observed. The voltammograms reflect that the immobilized GMP and DNA layers were gradually distorted at the biosensor incubation in ALA.

This behavior was confirmed by the differential pulse voltammetry (DPV) of anodic oxidation of the nucleotide base. Fig. 2 shows the DP voltammograms recorded at bare BDDE and GMP/BDDE before and after incubation in the ALA solution. The method of electrochemical impedance spectroscopy (EIS) is usually used to probe the interfacial properties of a modified electrode surface (Zhuo et al., 2005). The total impedance is determined by several parameters such as electrolyte resistance $\left(R_{\mathrm{s}}\right)$, the capacitance $\left(C_{\mathrm{dl}}\right)$, charge transfer resistance $\left(R_{\mathrm{ct}}\right)$, and Warburg element $\left(Z_{\mathrm{w}}\right)$. 

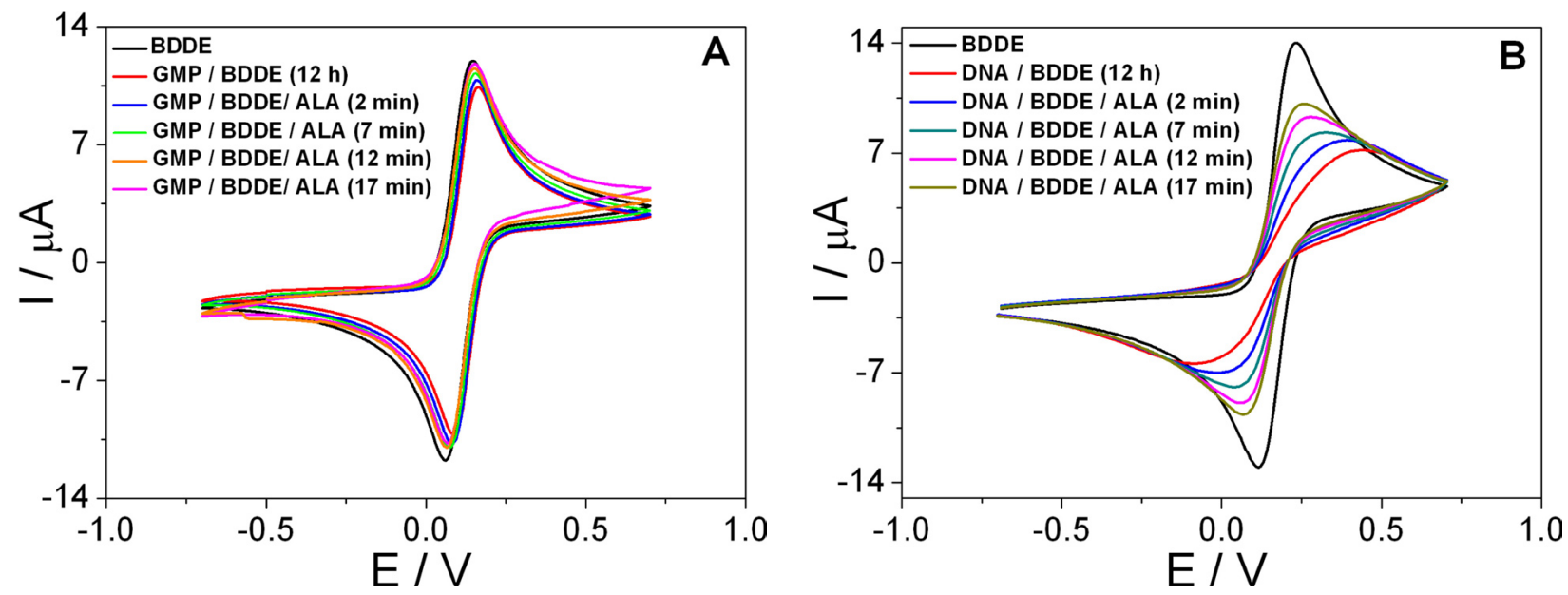

Fig. 1. $\mathrm{CV}$ records of $1 \times 10^{-3} \mathrm{~mol} / \mathrm{L}\left[\mathrm{Fe}(\mathrm{CN})_{6}\right]^{3-/ 4-}$ in $0.1 \mathrm{~mol} / \mathrm{L}$ PBS $(\mathrm{pH}=6.9)$ on the bare BDDE and GMP/BDDE (A) and DNA/BDDE (B) before and after incubation in ALA solution $\left(\mathrm{c}=4.5 \times 10^{-5} \mathrm{~mol} / \mathrm{L}\right)$ for given time.

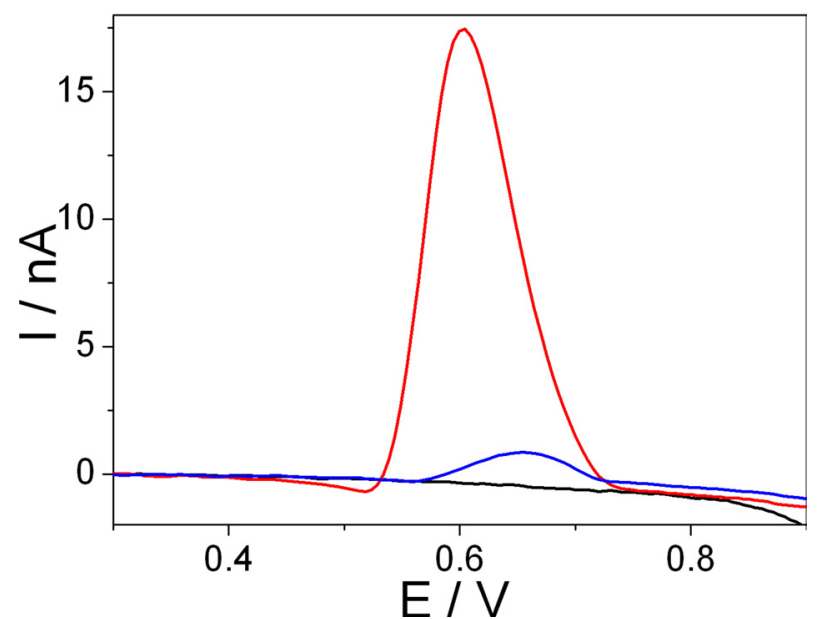

Fig. 2. DPV records of $0.1 \mathrm{~mol} / \mathrm{L}$ PBS $(\mathrm{pH}=6.9)$ for the bare BDDE (-) and GMP/BDDE before (-) and after (-) incubation in ALA solution $\left(4.5 \times 10^{-5} \mathrm{~mol} / \mathrm{L}\right)$ for $17 \mathrm{~min}$.

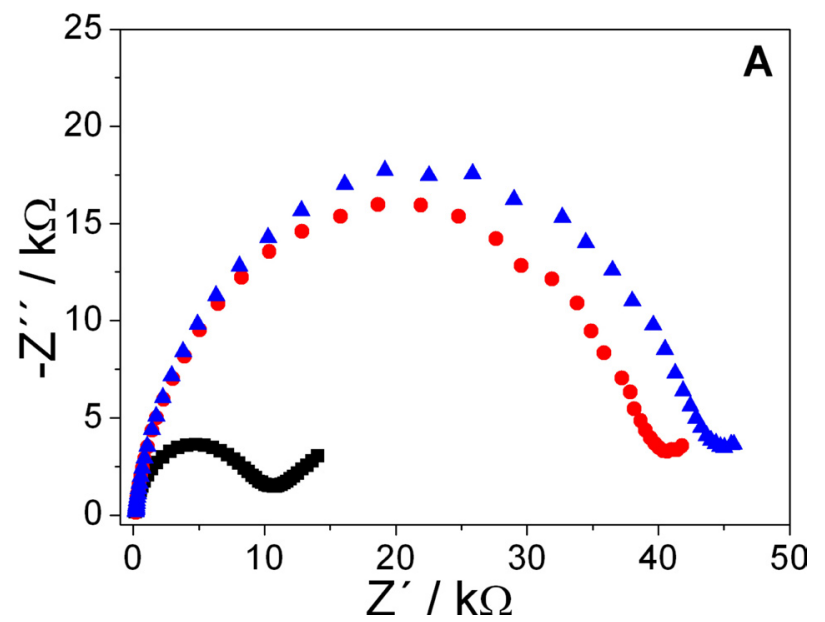

The EIS results are depicted in Fig. 3. The Nyquist plot curves show a decrease of the semicircle radius after 17 min incubation in ALA indicating the GMP and the DNA layer degradation. For the GMP/ BDDE, it is coupled with the lowering of the charge transfer resistance $\left(R_{\mathrm{ct}}=35.9 \mathrm{k} \Omega\right)$ with respect to the value corresponding to GMP/BDDE before incubation $\left(R_{\mathrm{ct}}=39.7 \mathrm{k} \Omega\right)$. For a comparison, the resistance for the bare BDDE electrode was $R_{\mathrm{ct}}=9.5 \mathrm{k} \Omega$.

Effect of time of the biorecognition element immobilization on the BDDE surface was also tested. Based on the CV measurements, the GMP survived portion (surv GMP) after the incubation of the modified electrode in the ALA solution was evaluated as the normalized current value $\left(\Delta I_{\text {rel }}\right)$ calculated as mentioned in the Experimental (Table 1). The data obtained indicate stepwise degradation of the biorecognition element layer in both cases. Similarly, an effect of the ALA con-

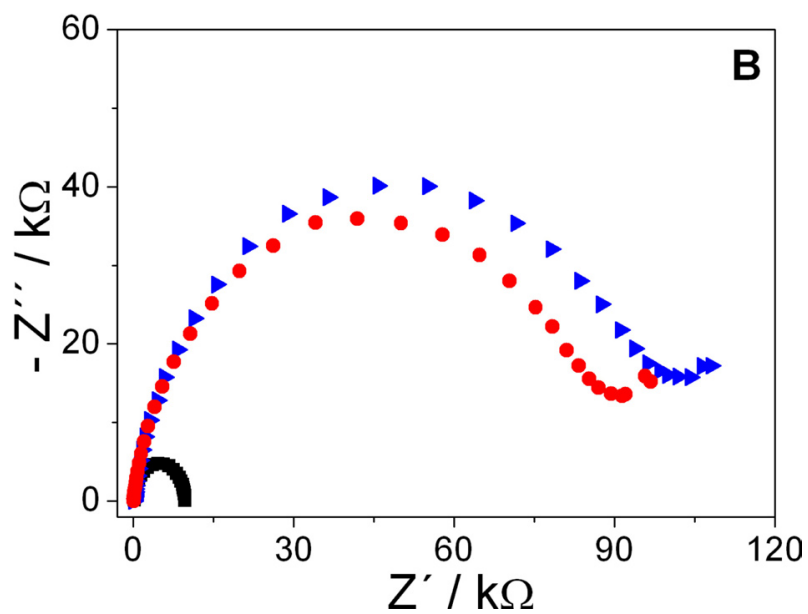

Fig. 3. Nyquist plot curves of $1 \times 10^{-3} \mathrm{~mol} / \mathrm{L}\left[\mathrm{Fe}(\mathrm{CN})_{6}\right]^{3-/ 4-}$ in $0.1 \mathrm{~mol} / \mathrm{L} \mathrm{PBS}(\mathrm{pH}=6.9)$ obtained for the unmodified BDDE ( $\mathbf{\square})$, GMP/BDDE (A), DNA/BDDE (B) before $(\boldsymbol{\Delta})$ and after $(\bullet)$ incubation in ALA solution $\left(4.5 \times 10^{-5} \mathrm{~mol} / \mathrm{L}\right)$ for $17 \mathrm{~min}$. 
centrations during the GMP/BDDE incubation on the portion of survived immobilized GMP was evaluated. Table 2 shows larger degradation of the GMP layer at higher concentration of ALA.

Tab. 1. Effect of GMP immobilization time on the portion of immobilized biorecognition element which survived the GMP/ BDDE incubation in the ALA solution $\left(4.5 \times 10^{-5} \mathrm{~mol} / \mathrm{L}\right)$ for given time.

\begin{tabular}{ccc}
\hline \multirow{2}{*}{$\begin{array}{c}\text { Incubation time } \\
(\min )\end{array}$} & \multicolumn{2}{c}{ Immobilization time $(\mathrm{h}) / \Delta I_{\text {rel }}(\%)$} \\
\cline { 2 - 3 } & 12 & 15 \\
\hline 2 & 71.2 & 85.3 \\
7 & 41.7 & 76.7 \\
12 & 23.0 & 70.3 \\
17 & 11.8 & 65.5 \\
\hline
\end{tabular}

Tab. 2. Effect of ALA concentrations on the portion of immobilized biorecognition element which survived the GMP/BDDE (12 h of GMP immobilization) incubation in the ALA solution for given time.

\begin{tabular}{ccc}
\hline \multirow{2}{*}{$\begin{array}{c}\text { Incubation time } \\
(\mathrm{min})\end{array}$} & ALA concentration $(\mathrm{mol} / \mathrm{L}) / \Delta I_{\text {rel }}(\%)$ \\
\cline { 2 - 3 } & $4.5 \times 10^{-6}$ & $4.5 \times 10^{-5}$ \\
\hline 2 & 85.1 & 71.2 \\
7 & 78.2 & 41.7 \\
12 & 76.9 & 23.0 \\
17 & 73.9 & 11.8 \\
\hline
\end{tabular}

\section{Conclusions}

In this paper, two electrochemical (CV and DPV) and one electrical (EIS) measurements for the evaluation of stability and interaction of the biorecognition element layer attached to the surface of the BDDE are presented as effective approach to the investigation of novel analytical tools such as chemically modified electrodes and biosensors based on boron doped diamond. Possibility of a surface attachment of the nucleotide to BDDE together with indication of its sensitivity to a chemical such as the pesticide alachlor is demonstrated.

This contribution enriches the knowledge on characterization of modern and perspective electrochemical (bio)sensors for the investigation of interaction of chemicals like pesticides with the biological recognition elements. This makes the utilized electrode promising for future application in the environmental analytical chemistry.

\section{Acknowledgement}

This work was supported by Scientific Grant Agency VEGA of the Slovak Republic (Projects No. 1/0051/13 and
1/0361/14) and the Slovak Research and Development Agency under the Contract No. APVV-0797-11.

\section{References}

ApiluxA, Tabata M, ChailapakulO(2007)Bioelectrochem. 70: 435-439.

Bagal MV, Gogate PR (2012) Sep. Purif. Technol. 90: 92-100.

Bernasinska J, Duchnowicz P, Koter-Michalak M, Koceva-Chyl A (2013) Environ. Toxicol. Pharmacol. 36: 368-377.

Creus A, Ostrosky-Wegman P, Marcos R (2011) Mutagenesis 26: 19-26.

Dryhurst G (1971) Anal. Chim. Acta 57: 137-149.

Garbellini GS, Uliana CV, Yamanaka H (2011) J. Braz. Chem. Soc. 27: 1241-1245.

Garbellini GS, Uliana CV, Yamanaka H (2013) J. Braz. Chem. Soc. 24: 1942-1949.

Greene SA, Pohanish RP (Eds.) (2005) Sittig's Handbook of Pesticides and Agricultural Chemicals, William Andrew Publishing, Norwich, NY.

Ivandini TA, Honda K, Rao TN, Fujishima A, Einaga Y (2007) Talanta 71: 648-655.

Jackson SP, Bartek J (2009) Nature 461: 1071-1078.

Karasz FE, Jama CT, Delabouglise D, Bouvier P, Livache T, Mailley P, Marcus B, Mermoux M, Petit JP, Szunerits S, Vieil E (2005) Electroanalysis 17: 517-526.

Knickerbocker T, Strother T, Schwartz MP, Russell Jr. JN, Butler JE, Smith LM, Hammers RJ (2003) Langmuir 19: 1938-1942.

Labuda J, Ovádeková R, Galandová J (2009) Microchim. Acta 164: 371-377.

Labuda J (2011). In: Mascini M, Palchetti I (Eds.) Nucleic Acid Biosensors for Environmental Pollution Monitoring (pp 121-140). Royal Society of Chemistry, Cambridge.

Labuda J, Vyskočil V (2014). In: Ota K, Kreysa G, Savinell RF (Eds.) Encyclopedia of Applied Electrochemistry (pp 346-350). Springer, Berlin.

Nowicka AM, Kowalczyk A, Stojek Z, Hepel M (2010) Biophys. Chem. 146: 42-53.

Oliveira SCB, Oliveira-Brett AM (2010a) Anal. Bioanal. Chem. 398: 1633-1641.

Oliveira SCB, Oliveira-Brett AM (2010b) J. Electroanal. Chem. 648: 60-66.

Oliveira-Brett AM, Piedade JAP, Silva LA, Diculescu VC (2004) Anal. Biochem. 332: 321-329.

Paleček E (1960) Nature 188: 656-657.

Ravera M, Bagni G, Mascini M, Osella D (2007) Bioinorg. Chem. Appl., Article ID91078.

Słaba M, Szewczyk R, Piatek MA, Długonski J (2013) J. Hazard. Mater. 261: 443-450.

Svítková J, Machková M, Šatkovská P, Cinková K, Švorc L (2012) Acta Chimica Slovaca 5: 42-46.

SvítkováJ,IgnatT,ŠvorcL, LabudaJ, BarekJ(2015)Crit.Rev. Anal. Chem. DOI: 10.1080/10408347.2015.1082125.

Švorc L', Tomčík P, Svítková J, Rievaj M, Bustin D (2012) Food Chem. 135: 1198-1204.

Švorc L, Rievaj M, Bustin D (2013a) Sens. Actuators B 181: 294-300.

Švorc L, Sochr J, Svítková J, Chýlková J (2013b) Electrochim. Acta. 111: 242-249. 
Švorc L', Kalcher K (2014) Sens. Actuators B 194: 332-342.

Švorc L, Cinková K, Samphao A, Stanković DM, Mehmeti E, Kalcher K (2015) J. Electroanal. Chem. 744: 37-44.

Troupe CE, Drummond IC, Graham C, Grice J, John P, Wilson JIB, Jubber MG, Morrison NA (1998) Diamond Related. Mater. 7: 575-580.

Wang J (2008) Chem. Rew. 108: 814-825.

Yang W, Auciello O, Butler JE, Cai W, Carlisle JA, Gerbi JE, Gruen DM, Knockerbocker T, Lasseter TL, Russell Jr. JN, Smith LM, Hammers RJ (2002) Nature Mater. 1: 253-257.
Yin H, Zhou Y, Ma Q, Liu T, Ai S, Zhu L (2011) Microchim. Acta 172: 343-349.

Zhu JH, Yan XL, Liu Y, Zhang B (2006) J. Hazard. Mater. 135: 94-99.

Zhuo S, Yuan R, Chai ZQ, Tang DP, Zhang Y, Wang N, Li XL, Zhu Q (2005) Electrochem. Commun. 7: 355-360. 